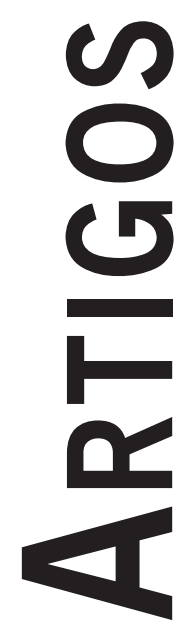




\title{
NUDEZ SOCIAL E O CORPO RE-VESTIDO NA PERSPECTIVA DA ABORDAGEM GESTÁLTICA
}

\author{
Social Nudity and the Body Reclothed in the Gestalt Perspective \\ Desnudez Social y el Cuerpo Re-Vestido en la Perspectiva del Abordaje Gestáltico
}

Jorge Ponciano Ribeiro

Marta Azevedo Klumb Oliveira

\begin{abstract}
Resumo: Este estudo discute a vivência da nudez social e do corpo re-vestido como um processo de auto-regulação, de ampliação de consciência sobre si mesmo e sobre o mundo a partir do olhar da Abordagem Gestáltica. Considera a experiência da nudez como um campo em mudança, como um espaço vital, no qual a pessoa lida com seu "mundo da consciência" a partir da sensação de seu corpo des-nudo, em ação. Toma o conceito de corpo-próprio de Merleau-Ponty como referência e mote para dialogar com diversos construtos da abordagem gestáltica tais como figura-fundo, awareness, campo, contato, autorregulação organísmica e ajustamento criativo. Apresenta a vivência do naturismo como caminho de convergência através da consciência de que pessoa, natureza e planeta estão interligados e formam um todo vivo, indivisível e organizado. Afirma que a realidade relacional, em um campo naturista, é produzida por variáveis psicológicas e não-psicológicas, ligadas, entre outros possíveis sentimentos, a uma conexão com a paz, a tranquilidade e a alegria de simplesmente estar, aqui-agora, existindo, em ato.
\end{abstract}

Palavras-chave: Nudez social; Ajustamento criativo; Gestalt-terapia; Fenomenologia.

Abstract: This paper discusses the experiences of social nudity and body cover up in order to expand awareness about oneself and about the world from a look of Gestalt Approach. Considering the creation of a field, as a living space, where the person can deal with his/her "world of consciousness", experimenting and experiencing their own experiences. It takes the concept of body-own Merleau-Ponty as a reference for dialogue with diverse conceptions of Gestalt Approach such as figure-ground, awareness, field, contact, organismic self-regulation and creative adjustment. It also presents the experience of nudism as a path of convergence between people. It brings awareness that people, nature and the planet are interconnected and form a living, indivisible and organized whole. Lastly, it states that the relational reality in a naturalism camp is produced by psychological and non-psychological. Linking the feeling of connection with peace variables such as the tranquility and joy of simply existing in the 'now' is the phenomenal reality experienced by naturist.

Keywords: Social nudity: Creative adjustment; Gestalt-therapy; Phenomenology.

Resumen: Este estudio discute la experiencia de la desnudez social, el cuerpo re-vestido como un proceso de autorregulación y de ampliación de la consciencia sobre sí mismo y sobre el mundo del punto de vista del abordaje gestáltico. Considera la experiencia de la desnudez como un campo en mudanza, de transformación, como un espacio vital donde la persona trabaja con su "mundo de la consciência", partiendo de la sensación de su cuerpo desnudo en acción. Este ensayo toma el concepto de cuerpo propio de Merleau-Ponty como referencia y punto de partida para dialogar con diversos constructos del enfoque gestáltico tales como: figura-fondo, awareness, campo, contacto, auto-eco-regulación organísmica, ajuste creativo. Presenta la experiencia del Naturismo como camino de convergencia a través de la consciencia de que persona, naturaleza y planeta están interligados y forman un todo vivo, indivisible y organizado. Afirma, también, que la realidad relacional en un campo naturista es producida por variables psicológicas y no psicológicas, unidas entre otros posibles sentimientos, a una conección con la paz, tranquilidad y alegría de simplemente estar aquí-ahora, existiendo de hecho.

Palabras-clave: Gestalt-terapia; Desnudez social; Auto-eco-regulación; Fenomenología.

\section{Introdução}

Os pássaros cantavam e rendiam as corujas na barra da madrugada. O dia envelopava a noite e a endereçava para o outro lado do mundo anunciando sua chegada implacável. A experiência humana faz com que cada dia contenha o infinito em si mesmo, tal qual somos infinitos na nossa jornada diária do tempo de existir. Assim, fui adentrando a magia daquele dia. Passo a passo, sentia a textura do toque dos meus pés no chão, o ar adentrava nos meus pulmões com a delicadeza de quem pede licença, meus olhos se sentiam tocados pela beleza dos mil tons de azul do céu, minha pele sentia a aragem fresca a envolvendo e a convidando para um abraço em demora. Por vezes, percorria um arrepio espasmódico por toda minha extensão de pele e as águas do corpo ameaçavam se lançarem do abismo dos olhos delatando ao universo minha emoção incontida.

Naquele eterno instante, fui retirando de mim tudo que em mim excedia: as impurezas, a blusa, o embaraço, o jeans, as falsas verdades, tudo. Tudo que compõe a 
dimensão inesgotável do exagero da sociedade urbana tecnológica que transforma seres em reses. Acaso percebeste tu que "seres", lido de trás para diante, não altera a grafia? Somos tão únicos! Tão inteiros! Tão humanos!

A noção de tempo nesse momento já se havia alterado e, no agora daquele instante, era com kairós que eu dialogava. À medida em que caminhava, fui me deixando des-cobrir por tudo que de mim ou para mim emergia. A nudez, a natureza e eu nos fundíamos em uma só presença. Eu sou a nudez. Me vinha aos lábios uma vontade ingênua de simplesmente sorrir, me entregar ao momento e seguir com ele para o núcleo do tempo.

Peço licença ao leitor para iniciar esse diálogo a partir do relato desta experiência própria com a nudez em espaço aberto acercado pela natureza do Cerrado, para que a descrição da sensação sirva de mote para a compreensão de acontecimentos, como o sentido do corpo-presença em situação de nudez social e o sentido que assume quando tra-vestido por vestes outras que não a pele e que ora desejo discutir à luz de uma perspectiva fenomenológica.

A partir do momento em que somos lançados no mundo, cada um de nós passa a possuir a autoria de sua vida, inicia a construção do percurso de sua existência, aproxima-se de si mesmo em uma espécie de enamoramento, de autocontemplação ou se afasta de si em uma confluência disfuncional com o outro. Esta experiência não nos afasta, entretanto, da responsabilidade que temos sobre nós mesmos e aqui, talvez, a indumentária que nos reveste seja mais uma forma de nos distanciarmos de nós mesmos, do outro, perdendo a originalidade de nos sentirmos, pura e simplesmente, vestidos de pele.

Esse estudo não pretende fazer uma discussão sobre quem somos, embora a petulância existencialista seja intrínseca a nós, pois essa busca é quase uma emergência derivada da consciência de sabermos que somos únicos nesse mundo, diferentes de todas as outras pessoas e de sabermos que esta busca não está nem um tempo atrás, nem à frente desse instante de nós mesmos.

Em uma caminhada, em uma praia naturista, conversando com uma pessoa, recém praticante de nudismo social de aproximadamente 35 anos, ela me confessou, quando interpelada sobre o sentido de usar roupas, que a roupa é uma “extensão de nossa personalidade” e que, pelo modo como nos vestimos, damos aos outros, "pistas de quem somos”. Fiquei tomada por essa explicação, pois as roupas, ao contrário do que possa parecer, são, muitas vezes, pistas mais evidentes de "quem não somos". Intrigou-me a ideia de que a roupa possa sinalizar uma "extensão de nossa personalidade”, porque o estilo da roupa talvez me permita conhecer mais acerca da faixa salarial da pessoa do que do modo como se sente no mundo.

A roupa tem sido, entretanto, um jeito milenar de intermediar nossa relação com o mundo e este fato cria uma espécie de segunda natureza na nossa relação com as pessoas. Nossa roupa, nossas vestes estão incrustradas no nosso DNA psicológico e social. A roupa comunica. A roupa nos comunica e é importante que não se perca esta perspectiva. Seria uma ingenuidade, no que diz respeito ao uso do corpo, negar o quão difícil é para muitos, mulheres e homens, o desnudar-se socialmente, sobretudo quando se sente estar rompendo com costumes seculares de ter e ver a roupa como proteção, como defesa e, muitas vezes, como uma expressão clássica de uma visão religiosa de mundo e de pessoa.

Postos estes arrazoados, e sem demérito à complexidade da experiência em relação ao corpo, reafirmo a importância da experiência e da vivência da nudez social, do equilíbrio que ela é capaz de produzir em muitas pessoas, quando em harmonia com a natureza, sobretudo pelas vantagens que a prática da nudez social pode lhes proporcionar, por meio do resgate do sentido de ser um corpo vivo e próprio, de ser pessoa no seu estado original, tal como a natureza a criou, sem os disfarces que a sociedade terminou por impor ao corpo, às vezes de consequências inimagináveis. Some-se a isto, a escassez de literatura sobre tais benefícios.

O objetivo desse estudo é, pois, por meio de uma reflexão fenomenológica, de um jeito fenomenológico de pensar a realidade, aproximar-me do que seria a essência do corpo-presença que me chama, que me provoca a viver a partir de minha pele e, a partir daí, inferir algumas assertivas acerca da dimensão humana nesse tempo-espaço tortuoso no qual está contido o “tornar-se humano”, considerando o corpo-nu e o corpo-[re]vestido, um corpo, ao mesmo tempo, enraizado na natureza ${ }^{1}$ e um corpo enraizado na cultura.

Nesse sentido, tanto quanto possível, suspendo meu sujeito empírico e psicológico, retendo, entretanto, meu sujeito da experiência vivencial. Esse percurso sensação-razão-ação diz muito de cada um de nós, de mim e de ti, embora não se possa saber quanto de ti habita em mim e quanto de mim habita em ti.

Convido-te então, dileto leitor, a mergulhar comigo neste mar de possibilidades, na esperança de que, passando por lugares nunca dantes navegados, possamos descobrir no corpo-nu belezas nunca dantes exploradas.

\section{Caminhando na direção de si mesmo}

Proponho que testemunhemos juntos algumas trilhas cognitivas que me permitem escolher e, talvez, como asseverava Edith Stein, possamos, ao final do percurso, chamar esse estudo de nossa "propriedade espiritual" (Bello, 2000, p. 83).

\footnotetext{
Aqui, tomo o referencial de "natural" para toda e qualquer nudez, ainda que haja um corpo nú enraizado na cultura, seja por cicatrizes cirúrgicas resultante da evolução da ciência curativa ou estética (plásticas, próteses de silicones e/ou outros artifícios).
} 
Inicio, pois, por uma compreensão do conceito de epoché em Husserl, para, em seguida, entender como Merleau-Ponty constitui o corpo-presença e então, ir tecendo saberes outros, que coexistam a partir da experiência pré-reflexiva descrita acima. Assim, segundo Zilles (2002), citando Husserl:

Em nossas afirmações fundamentais nada pressuporemos, nem sequer o conceito de Filosofia, e assim queremos ir fazendo adiante. A epoché filosófica, que nos propusemos praticar, deve consistir, formulando-a expressamente, em nos abstermos por completo de julgar acerca das doutrinas de qualquer filosofia anterior e em levar a cabo todas as nossas descrições no âmbito desta abstenção. (p. 22)

Observo que o conceito epoché, conforme cunhado por Husserl, é básico para uma atitude fenomenológica que implica em "pôr de lado" o mundo físico (objetos espaço-temporais) e passar a lidar com o "mundo da consciência”, formado por minhas próprias vivências. Cabe aqui perguntar o que é, o que se entende por corpo-presença? Ao falar de nudez, falo de corpo, do corpo desnudo. Mas o que é ser-corpo? Ao questionar Merleau-Ponty, segue o que ele me responde:

Corpo é sempre outra coisa que aquilo que ele é, sempre sexualidade ao mesmo tempo que liberdade, enraizado na natureza no próprio momento em que se transforma pela cultura, nunca fechado em si mesmo e nunca ultrapassado. Que se trate do corpo do outro ou de meu próprio corpo, não tenho outro meio de conhecer o corpo humano senão vivê-lo, quer dizer, retomar por minha conta o drama que o transpassa e confundir-me com ele (Merleau-Ponty, 1999, p. 269).

Em Merleau-Ponty, é preciso "viver o corpo”, "confundir-me com ele”, ser ele. Para além, entretanto, da inequívoca poética do filósofo sobre o corpo, pergunto-me, como é, de fato, viver o meu corpo? O corpo, por implicar em subjetividade, senhor silencioso do próprio sentido, é talhado pela historicidade cultural, regido pela noção de auto-eco-organização, carimbado pelo paradigma ecológico vida-natureza-homem-sociedade e por ser feito de igual matéria do mundo (água, terra, fogo e ar), deixa-se naufragar no tempo de Cronos e imputa sentido aos fatos, tornando-se autor de seu acaso.

Vem-me à mente a assertiva de William Blake (citado por Villamarín, 2003, p. 92), quando afirma que "o homem não tem um corpo separado da alma. Aquilo que chamamos de corpo é a parte da alma que se distingue pelos seus cinco sentidos”, ou seja, a noção de realidade nos é dada pelo corpo, um corpo que toca e é tocado pelo mundo, um corpo-consciência. Um corpo cujos sentidos não são meros receptores passivos do real, mas são ativos na percepção do mundo, na relação única que se estabe- lece com o mundo. A percepção é um acontecimento da corporeidade $^{2}$ e, como tal, da existência.

Pensando fenomenologicamente, essa ideia traz à discussão a questão da intencionalidade do movimento, porque as sensações, nesta perspectiva filosófica, se associam a movimentos que acenam para a manifestação de um gesto que se configura em uma criação, em novas possibilidades de compreensão de diferentes situações existenciais. Para Ghiraldelli Jr (2014, p. 5):

São múltiplos os sentidos que a intencionalidade motora pode expressar (...). Corpo sem intenção ou sem que se possa cogitar sobre sua intenção, não é body, mas corpse. O corpo humano que é sempre corpo-e-movimento é intencional, um conjunto que envolve sons e gestos.

Nesta mesma linha, Merleau-Ponty reforça a teoria da percepção fundada na experiência do sujeito encarnado, do sujeito que olha, sente e, nessa experiência do corpo fenomenal, reconhece o espaço como expressivo e simbólico. "Pode-se dizer ao pé da letra que o espaço se sabe a si mesmo através do meu corpo" (Merleau-Ponty, 1975 p. 437). Não haveria espaço para mim, se eu mesma não fosse um corpo no mundo, ou seja, eu sou no espaço. Falar de sujeito encarnado implica, portanto, em falar de corpo, de tempo, do outro, da afetividade, do mundo da cultura e das relações sociais. A experiência perceptiva é, portanto, uma experiência corporal.

Segundo Ribeiro (2006, p. 123): "figura-fundo são dois processos que se alternam, no qual ora um, ora outro se mostra ou se revela ao sujeito como uma possibilidade de inclusão perceptiva”. Considerando que a figura assinala a aparência que as coisas tomam, tal como se revelam, e sob a qual a identificamos, e considerando que o fundo é um campo perceptivo total, entendo que a relação figura-fundo é constitutiva da forma como percebemos a realidade e que o corpo é a resultante desta relação.

Um encontro com pessoas em situação de nudez social tanto pode ser percebido como uma experiência de vergonha, de erotismo embriagado de desejo ou mesmo de acanhamento como pode, também, entre pessoas que partilham o ideal naturista, ser percebido de um modo tão verdadeiramente simples, tão desprovido de erotismo, de desejo que a figura que emerge seja de total equilíbrio e integração, onde cada parte de seu corpo e seu corpo em cada uma de suas partes, se apresenta como uma única configuração, uma gestalt. Assim, seios e glúteos não são mais relevantes na inteireza de seu corpo do que nariz e cotovelo.

Essa consciência é fundante de um estilo de vida que se assenta numa visão de saúde baseada no princípio holístico de que "tudo está ligado a tudo, de que tudo mu-

\footnotetext{
2 Destaco que o conceito de "corporeidade" neste estudo se assenta na exata medida da compreensão de Husserl sobre o conceito, ou seja, na expressão: “eu sou um corpo" e não "eu tenho um corpo”.
} 
da e, sobretudo, de que tudo é um”. É uma vivência "nua e crua", com o perdão do trocadilho, do método da epoché, quando, numa experiência radical, excluo todo saber e experiências anteriores e sem desejo e sem memória, estabeleço um contato "ingênuo" com a própria nudez, buscando compreendê-la a partir do sentido que emerge da percepção da própria totalidade, das inter-relações entre as partes do corpo entre si e estas com sua totalidade, no mundo.

A prática do nudismo, da nudez social, em campo naturista, despertou em mim uma nova consciência de aceitação do outro, assim como eu sou, assim como ele é. Os chamados "defeitos do corpo", nossas imperfeições podem ser percebidas como as inscrições de cada um e de todos na vida, resultado da nossa relação com o mundo. Traduzem a cada um de forma única.

\section{A experiência da vergonha}

A vivência do naturismo como uma nudez social, uma nudez coletiva me permite expandir e viver a expressão "todo outro é um outro eu mesmo" de Merleau-Ponty (1974, p. 142). Quando meu corpo-consciência toca teu corpo-consciência, te sinto em mim e me sinto em ti. Esta percepção se consolida, quando, entre meus pares, em um ambiente onde se pratica o nudismo, que integra o naturismo, sinto meu duplo errante mais inteiro em mim e me integro com os "comigos de mim mesma" de modo próprio.

Para Merleau-Ponty (1974) o corpo-presença é, ao mesmo tempo, uma estrutura psicológica e histórica, um entrelaçamento de tempos distintos: do tempo natural, do tempo afetivo e do tempo histórico. O sentido que atribuo ao que vivo vai tecendo estreito diálogo entre o tempo, o espaço, meu corpo, o mundo que habito e as outras pessoas e, embora o mundo já existisse antes de mim, ele não está inteiramente constituído, depende também de minhas ações para se constituir como mundo. Assim, nas teias do agora, busco um diálogo com os testemunhos religiosos, históricos-antropológicos e filosóficos sobre o ser-nu, na intenção explícita de ouvir as vozes dos tantos tempos do Ser.

Perscrutando nossa origem, a origem do ser-corpo lançado no mundo a partir de um viés cristão, encontro, nos registros Bíblicos (Gênesis, cap. 2, vs. 15-18 e cap. 3, vs. 1-14), uma passagem de Adão e Eva, em diálogo com Deus, quando foram expulsos do Paraíso por terem comido o fruto proibido da Árvore do Conhecimento. Até, então, eles não tinham o sentimento de "vergonha" associado à nudez. Somente depois que comeram do fruto proibido da Árvore do Conhecimento é que despertaram a consciência de estarem nus e essa consciência trouxe, em seu bojo, o sentimento de "vergonha".
Adão e Eva descobrem a vergonha da nudez depois de provar o fruto da Árvore do Conhecimento ("No dia em que comerem desse fruto, seus olhos se abrirão...”). A vergonha é a consequência direta do conhecimento da awareness, diríamos nós, da consciência de si -, e é imediatamente associada à exposição de si mesmo, à nudez, ao olhar do outro (Robine, 2006, p. 155).

Aqui, vale destacar a sábia expressão do Papa São João Paulo II a respeito da vergonha, segundo a John Paul II's Theology of the Body (TOB May 14, 1980 p. 113):

Sua nudez, longe de ser de pouca importância, diz sobre o imenso amor de um para o outro e sobre a pureza de seus corações. Uma vez que a vergonha é resultado de ser visto como um objeto a ser usado por outra pessoa, Adão e Eva não sentindo vergonha demonstra-nos que ambos viam e recebiam um ao outro como um dom e procuravam apenas dar-se um ao outro, para não usar o outro. Eles contemplaram o outro com os olhos de Deus, que "viu tudo o que fizeram, e eis que era muito bom "(Gn 1:31). Eles leram no corpo do outro, o que era um sinal da outra pessoa, uma linguagem de amor, que cada um acolhia e retribuía. ${ }^{3}$

A vergonha ou a falta dela, estabelecida como uma "função interior", segundo afirma Sua Santidade, poderia ser compreendida também a partir da teoria lewiniana do Espaço Vital, onde fica claro que a variável psicológica "vergonha" não fazia parte da totalidade do campo, dos fatos que determinavam o comportamento de Adão e Eva no Paraíso naquele momento.

Assim, desde a origem mitológica de nossa condição humana, encontram-se associados com a experiência da vergonha: consciência, conhecimento, olhar do outro, sedução, desejo, nudez, ruptura de confluência, introjeção, projeção, culpa... fenômenos que o Homem nomeia: "VIVER" (Robine, 2006, p. 156).

O campo psicológico não incluía a "vergonha" como pressuposto da nudez social. Quão real, talvez até poético, me parece o insight de que o campo do nudismo social, no naturismo, na medida em que também não inclui a "vergonha", como dinâmica do campo psicológico, nos remete à ideia do Paraíso.

Do ponto de vista histórico-antropológico, um impor-

\footnotetext{
Their nakedness, far from being of little significance, says volumes about their love for each other and about the purity of their hearts. Since shame is a result of being viewed as an object to be used by another person, Adam and Eve's lack of shame demonstrates to us that they both saw and received each other as a gift and sought only to give themselves to one another, not to use the other. They beheld the other with God's eyes, who "saw everything he had made, and behold, it was very good" (Gen. 1:31). They read in each other's body, which was a sign of the other person, a language of love, which each welcomed and reciprocated. (Texto original)
} 
tante testemunho foram as Cartas de Pero Vaz de Caminha ao chegar às terras de Santa Cruz e mirar, ao longe, as cenas da fluidez dos seus habitantes nativos com a natureza tropical. Infiro um regozijo de cor, calor e espanto para os anos de 1500, quando o olhar europeu toca as cenas do atlântico sul. Assim relata sua visão à Corte Portuguesa segundo consta no acervo digital do Departamento Nacional do Livro (Ministério da Cultura):

(...) eram pardos, todos nus, sem coisa alguma que lhes cobrisse suas vergonhas. (...) Ali andavam entre eles três ou quatro moças, bem moças e bem gentis, com cabelos muito pretos, compridos pelas espáduas, e suas vergonhas tão altas, tão cerradinhas e tão limpas das cabeleiras que, de as muito bem olharmos, não tínhamos nenhuma vergonha. Ali por então não houve mais fala ou entendimento com eles, por a barbaria deles ser tamanha, que se não entendia nem ouvia ninguém. (...) E uma daquelas moças era toda tingida, de baixo a cima daquela tintura; e certo era tão bem-feita e tão redonda, e sua vergonha (que ela não tinha) tão graciosa, que a muitas mulheres da nossa terra, vendo-lhe tais feições, fizera vergonha, por não terem a sua como ela (...) também andavam, entre eles, quatro ou cinco mulheres moças, nuas como eles, que não pareciam mal. Entre elas andava uma com uma coxa, do joelho até o quadril, e a nádega, toda tinta daquela tintura preta; e o resto, tudo da sua própria cor. Outra trazia ambos os joelhos, com as curvas assim tintas, e também os colos dos pés; e suas vergonhas tão nuas e com tanta inocência descobertas, que nisso não havia nenhuma vergonha (p. 2-7).

"Vergonha", palavra recorrente no léxico da nudez, de acordo com o dicionário Michaelis da Língua Portuguesa Online, trata-se de um "Rubor de ação feita contra o decoro, contra a decência ou Sentimento de desgosto que excita em nós a ideia ou o receio da desonra”

É verdade que a vergonha é parte integrante da experiência humana da vida, na dialética exibir-inibir e que o Homem soube inventar inúmeros meios para tentar contorná-la. Assim, para viver no campo da vergonha, a Sociedade nos oferece, por vezes, a possibilidade de morrer no campo da honra (Robine, 2006, p. 168).

Se a nudez está ligada à desonra, às vestimentas, em um olhar merleau-pontyano, podem ser uma espécie de recalcamento do corpo próprio, da integralidade do sistema “eu-outro”. Há, aqui, uma referência necessária à alteridade ou à nossa relação com um mundo comum. Segundo Merleau-Ponty "é justamente meu corpo que percebe o corpo do outro, encontrando nele um prolongamento milagroso de suas próprias intenções, uma maneira familiar de se relacionar com o mundo" (Merleau-
-Ponty, 1999, p. 474). Esse posicionamento me leva a refletir que, se tocar e ser tocado, tal qual o entrelace das mãos esquerda e direita, é um gesto único, meu corpo-des-vestido e meu corpo-social, de igual modo, também o são. Meu corpo social é um prolongamento do meu corpo-des-vestido. Somos síntese de corpos vários, em intrínseca relação no mundo.

Do ponto de vista filosófico, é importante recordar o romantismo do "mito do bom selvagem" de Rousseau, quando afirmava que o ser humano é bom por natureza, mas viver em sociedade pode causar sua degradação moral. O processo civilizatório seria, portanto, degenerativo da espécie humana na medida em que o distanciaria da sua natureza. Leopoldi (2002) fazendo alusão à Rousseau, destaca:

Para Rousseau (1978), o ambiente natural extremamente abundante e acolhedor, a ponto de parecer ter sido criado na medida exata para servir ao homem particularmente em termos de recursos alimentares, sendo, aliás, a preservação uma das poucas preocupações, senão a única, do homem no estado de natureza. "Suas módicas necessidades", diz Rousseau, "encontram-se tão facilmente ao alcance da mão e ele está tão longe do grau de conhecimentos necessários para desejar adquirir outros maiores, que não pode ter nem previdência, nem curiosidade. O espetáculo da natureza, à força de se lhe tornar familiar, torna-se-lhe indiferente”. A relação homem-natureza é, portanto, permeada por um ingrediente idílico marcado por uma complementaridade absoluta entre aqueles elementos. O equilíbrio dessa relação só vai-se romper quando ela começa a inserir-se num contexto dominado pela sociedade e pela civilização com as consequências necessariamente negativas que elas trazem. A "nostalgia” do estado de natureza é tão mais profunda quanto é para Rousseau a impossibilidade do homem viver em sociedade de maneira tão pacífica e sadia quanto vivia naquele estado. Afinal, "a maioria de nossos males é obra nossa e (...) os teríamos evitado quase todos conservando a maneira de viver simples, uniforme e solitária que nos era prescrita pela natureza (p. 162).

\section{A natureza em harmonia com a natureza.}

Em Rousseau (1978), a natureza prescreve um modo de vida saudável, mas nós terminamos por realizar uma “socialização da natureza”, ao transformá-la e ao manter com ela uma relação doentia de usurpação, de agressão e até mesmo de finitude, sem que nos apercebamos de que

\footnotetext{
4 Permito-me, por uma questão de atualidade e gênero, substituir o termo "homem” de Rousseau por "Ser Humano" para designar a espécie humana.
} 
ambos nascemos e morreremos a um só tempo, dado que são entes de um só e mesmo ato relacional: ser humano-natureza, embora me pareça mais própria para expressar a dicotomia a seguinte expressão: ser humano/natureza, dada a cisão que temos visto ocorrer em atos insanos genocidas. Sim. Para que a grafia materialize a cisão.

Quando deslocamos o olhar dos discursos hegemônicos da religião e histórico-antropológico do colonizador, identificamos, na atualidade, pelo menos três grupos humanos que não percebem a nudez como vergonha ou desonra: as crianças, os índios, e, em certa medida, os naturistas. Quem sabe não seriam estes, uma espécie de "bons selvagens"?

A criança, muito discutida por Merleau-Ponty, talvez por sua percepção aquém da nossa percepção habitual, objetiva e cristalizada, me provoca a reativar essa percepção de origem, quando a separação entre eu e o outro não era tão marcante. A infância, adolescência, o estado adulto e a própria velhice são encaradas, no naturismo, como estados naturais do desenvolvimento físico e psíquico, nos quais o corpo-nu mais que o corpo re-vestido pode ser experienciado, visto, exatamente como é, a partir desses específicos momentos do desenvolvimento humano.

A apresentação dicotômica do mundo infantil pré-objetivo e harmonioso, por um lado, e do mundo adulto objetivo, por outro, não deve ser vista a partir de uma afirmação dialética que foca a atenção ora em um ponto do pêndulo, ora em outro e impede a compreensão do caminho que é preciso fazer para se ir de um a outro ponto. $\mathrm{Na}$ compreensão gestáltica da realidade, o conflito é visto como uma oportunidade criativa de expansão do self. Nesse sentido, “[...] as dualidades podem ser observadas como aspectos diversos do mesmo fenômeno e não como contradições irreconciliáveis" (Ribeiro, 1997, p. 72).

Desta forma, quando se chega à idade adulta, próxima do outro extremo do pêndulo, ao que tudo indica, nossa candura se desfaz, ou a trocamos por um maço de sentimentos introjetados, associados à "vergonha”; quando se embota nossa percepção aberta e criativa, passa-se a adotar uma lente fosca, opaca e empoeirada por um excesso de mundo, um exagero de normas, métricas sociais, padrões culturais espessos; inegavelmente um desajustamento criativo ao campo.

Somente voltando "às coisas mesmas", transcendendo, é possível reencontrar a inocência perdida, voltar além ou aquém de toda separação entre sujeito e objeto, eu e o outro e vislumbrar o vir-a-ser de algo que já é, o corpo des-vestido, nu, ao reproduzir o sentido original bíblico e "Ora um e outro, isto é, Adão e sua mulher estavam nus e não se envergonhavam” (Genesis, cap. 2, v. 25). A experiência e a vivência do nudismo se apresentam, aqui-agora, como caminho à integração de tais polaridades e abertura para novas configurações de campo.
Quanto aos índios ${ }^{5}$ cuja prática é a nudez, ressalta-se que também ali há os aspectos sócio-culturais. Identificamos por meio da pintura corporal, em quase todas as sociedades indígenas, um significado amplo e diverso, que vai desde a expressão da beleza à preparação para a guerra. A ornamentação corporal é uma segunda "pele” e se caracteriza como um atributo sócio-cultural. O estilo, a cor e o local da pintura no corpo expressam o "status" de cada pessoa, na tribo. A pintura corporal é figura, o corpo-nu, fundo, não existindo nenhuma orientação voltada para pintura dos órgãos genitais como um modo de escondê-los ou proibi-los ao olhar do outro.

Tanto na vivência da infância, quanto na vivência indígena, a nudez é uma espécie de confirmação do ser-nú, um modo de concessão da nudez em todo e qualquer espaço social. Aqui o corpo-pessoa é figura, a nudez é fundo.

O terceiro grupo humano são os naturistas. Aqui algo se difere. Diversamente da criança e do índio que não experimentam nem vivenciam uma consciência de proibição moral da nudez, os naturistas experimentam uma consciência moral da proibição da nudez social e por isso criam espaços-refúgio identificados como legítimos para prática da nudez social, nos quais convivem com a necessidade de um encontro com seu ser-nu no tempo e no espaço coletivos.

Um lugar de permissão onde a vergonha social que, em tese, acompanha a adultez, seja um elemento emocional inexistente, "proibido", interdito para a felicidade plena dos que experienciam o corpo-nu. Afinal de contas, à luz de um olhar eco-complexo que comporta ordem, interação, desordem e organização, o naturismo tenta ser uma forma possível de expressão do conceito de adaptação ao tentar reproduzir um paradigma de um viver próximo ao modo como a natureza nos apresenta à vida, corpos-nus.

A nudez, vivida naturalmente em sociedade e nas circunstâncias acima referidas, é uma experiência libertadora. O fato de se estar nu, junto de outras pessoas, auxilia na compreensão de diversos processos relativos às experiências vividas no antes do nosso agora, provoca uma maior e profunda awareness corporal, provoca na pessoa um dar-se conta da exata dimensão de quem ela é, desperta nela uma verdadeira sensação do sagrado pela sensação de desapego e desprendimento de ser um corpo simplesmente terra, altera sua percepção de contato diante dela e do mundo que a observa. A vivência ora da nudez, ora do corpo re-vestido diz muito ao naturista, cuja experiência com o corpo nu e com o corpo re-vestido se alternam em constante movimento de formação de figura e fundo, processos que explicitam nele alguns dos processos básicos de se ser ser-humano, como o medo, a coragem, o proibido, a liberdade.

\footnotetext{
5 O termo "índio" é tratado aqui, como referência às diversas etnias, sem distinção de idiossincrasias de cada uma por considerar que no bojo desse estudo importa a percepção da nudez de modo abrangente não sendo relevantes aspectos distintos de uma ou outra cultura. Registre-se que de modo algum, desrespeito as particularidades dos povos.
} 


\section{O corpo-nu sob um olhar teórico}

Ribeiro (2006) explicita estas experiências do ponto de vista gestáltico:

Awareness é uma consciência de apreensão de totalidades, como se todo meu ser se resumisse em um único ato de cognição emocional. [...] é a expressão vivenciada e consciente de que somos seres de relação, em um profundo dar-se conta por meio de uma sensação de integração de todas as minhas partes em um único ato de percepção interna (p. 74).

No estado de nudez colocamo-nos na posição radical de "ir às coisas mesmas", pois minha nudez é minha totalidade consciente, está tudo ali, nada falta, não se pode ir além da própria pele. Meu estado de nudez me possibilita vivenciar um dos mais fundamentais princípios da fenomenologia "resgatar a experiência imediata", pois meu corpo-nu é agora e só agora ele é capaz de me colocar radicalmente diante de mim mesma, sem subterfúgios, sem mentiras. Isso equivale dizer que estar aware é ser e estar responsável por dar sentido a toda forma de experiência e por formar novas gestalten que me conduzem a uma intencionalidade corporal que significa dar sentido ao que, de fato, tem sentido, naquele aqui-agora de um corpo-nu. Neste estado de nudez, o corpo está em profundo contato consigo, com o outro, com o mundo à sua volta, i.e., o contato é um processo psíquico por meio do qual a pessoa entra em relação consigo, com o outro e com o mundo em busca de uma diferenciação física, psíquica e emocional.

A partir dessas reflexões, infiro que o naturista cria um campo próprio ao ajustamento criativo, ou seja: "um processo pelo qual o corpo-pessoa, usando sua espontaneidade instintiva, encontra em si, no meio ambiente ou em ambos, soluções disponíveis, às vezes aparentemente não claras, de se auto-regular" (Ribeiro 2006, p. 64). Um campo, um estado psico-emocional, no qual o proibido passa a ser o desejável, o vergonhoso volta a ser natural, o mundo da fantasia é sentido com fronteiras mais definidas, um contato mais saudável consigo mesmo se estabelece, uma capacidade aprimorada de mergulhar em si mesmo e de perceber o mundo se concretiza. $\mathrm{O}$ contato com a própria nudez e com a do outro pode representar, assim, um processo ativo e consciente de ajustamento criativo, de auto-eco-regulação organísmica pela harmonia que se estabelece entre sujeito-objeto, pessoa-mundo. É esta, uma possibilidade legítima de entendimento teórico.

Nesta linha de compreensão, a experiência da nudez cria um campo relacional holístico através de uma auto-eco-regulação organísmica, ou seja:

o respeito à totalidade funcional do organismo, (...) o olhar-se e o comportar-se como um todo organizado e eficiente, o privilegiar as necessidades que gritam dentro de nós para serem saciadas, o olhar-se como uma pessoa inteira no mundo, o amor ao corpo como a casa na qual habitamos (Ribeiro, 2006 p. 56).

Esta experiência faz com que a vivência do contato aconteça e se torne visível à atividade dinâmica de ciclos sucessivos de satisfação de necessidades, no qual figuras que surgem de um fundo opaco se tornam configurações perfeitas, gestalten cheias.

O naturista reconhece a necessidade hegemônica do mundo humano urbano de vestir seus corpos-pessoas, reconhece essa necessidade dominante, aceita o fato de que a roupa satisfaça uma necessidade urbana e, de modo harmônico, ele consegue se retrair após o fechamento dessa gestalt cultural. Por outro lado, ele vivencia sua relação com a nudez, atualiza sua necessidade de vivenciar a nudez, a experiência plenamente e fecha essa gestalt vivendo prazerosamente sua experiência de estar em ação em um corpo-nu.

Assim, o naturista, ao ter sua liberdade, a partir de uma visão natural do corpo-nu, inibida para a atitude de "desnudar-se em praça pública", sob pena de cometer um ato reprovável de atentado ao pudor, e ao ter introjetado o "não pode" de um modo efetivo para o "ajustamento" social, ele, de certa maneira, entra em "acordo" com as normas sociais e deixa de produzir uma generalização do sentimento de proibição que afeta seu campo sócio-ambiental.

Consciente das proibições sociais e consciente, igualmente, da importância de viver o natural, ele cria um campo novo, propício para a livre expressão de seu corpo, i.e., ambientes, campos naturistas que se espalham por cada canto desse mundo em diferentes culturas. Nestes espaços, ele re-configura sua realidade existencial, resgata a possibilidade de uma experiência imediata com seu corpo e divide com outras pessoas a recuperação do sentido original do corpo humano des-vestido.

A necessidade do naturista de criar um campo de ação novo, que, entre outros benefícios, resgate o sentido existencial da nudez e supra a falta de uma literatura apropriada sobre o tema, que dêem sustentação ao modo de "ser natural", no mundo contemporâneo, desemboca na busca da compreensão e aceitação do naturismo em sociedades diferentes, em sua relação à pessoa em situação de nudez.

Carvalho (2013), na sua tese de doutorado, nos dá pistas que, ao tempo em que inquietam, instigam a uma imersão na direção de um entendimento sobre a natureza da ecopsicologia e seu papel, de ampliação da participação nas discussões sociais sobre os destinos da espécie humana e do planeta. Ele assim se expressa, quando faz alusão à Perls, Hefferline \& Goodman (1951/1997) e ao conflito entre pessoas e sociedade, posto ser tal qual a existência de pessoas antisociais e sociedades antipessoais: "sociedades antipessoais surgem por meio de mui- 
tas formas de violência... até as sutilmente brutais, que lhes tolhem a consciência de si, tornando a sobrevivência uma carga (p. 70) ".

Assim, no mesmo trilho, correm a explosão da ciência e do capital. Paralelas ligadas pelos dormentes da humanidade, que, paradoxalmente, ao tempo em que conecta este naquela, se aprisiona entre ambos e se estreita de modo tão ilusório que crê ser a eternidade um pertencimento pessoal, não conseguindo assentar o olhar para as complexas e múltiplas possibilidade de cuidar do patrimônio natural das gerações futuras. "O pós-moderno, enquanto condição de cultura nesta era, caracteriza-se exatamente pela incredulidade perante o meta-discurso filosófico-metafísico, com suas pretensões atemporais e universalizantes" (Lyotard, 1979/2015, p.viii).

Essa reflexão se faz importante no contexto desse estudo, porque dela deriva a inferência de que a falta do sentimento de pertencimento das pessoas ao que lhes é próprio e de respeito por si e pelo mundo, nos distancia, cada vez mais, do sentido do corpo-presença e, por sua extensão, da nudez de cada um e de todos nós. O naturismo, dentro desta perspectiva da ecopsicologia, faz todo o sentido.

Ribeiro (2006, p. 133) afirma que o homem não pode ser pensado sem o meio e discorre sobre a "autoecoregulação organísmica" como forma de tornar possível a vida humana no planeta. Ribeiro, a partir do conceito heraclitiano de que "tudo está ligado a tudo, de que tudo muda e tudo é um" afirma que a relação do ser humano com o ser humano exige uma conexão urgente para evitar o ponto de saturação e estrangulação do planeta.

Nesta perspectiva, estamos diante de um campo inovador, porque nele as mais diferentes pessoas experienciam a si próprias e aos outros com harmonia, respeito e cumplicidade. Este campo gerado pelos naturistas é, em si, revelador da busca pela boa forma, pela melhor configuração organismo-ambiente por meio do auto-cuidado e da consciência de que vida, natureza, homem e sociedade são interligados no cuidado com o outro e com o meio-ambiente. Um campo de convergência entre pessoas forma um fenômeno único, um todo organizado, articulado, indivisível, e gera uma realidade nova, o encontro respeitoso e harmonioso entre as diferenças existentes em um mundo à busca de se re-encontrar como uma configuração nutritiva.

O naturista almeja criar uma sociedade que respeite a pessoa, que não a desloque da sua condição de "natureza" viva, que beba a água da chuva e dance ao sol, ouvindo a música do vento, que não torne o planeta um simples objeto. Esse sentimento vem conquistando, cada vez mais, pessoas no mundo, talvez por uma saturação da mercantilização humana, talvez por uma exaustão da padronização artificial de nossos corpos.

\section{A legislação do Naturismo. Um pouco de história}

Segundo Pereira (2000), a Federação Internacional de Naturismo, que, na década passada, coordenava trinta e quatro federações nacionais, responsáveis por 850 clubes e mais de 1.500 praias, relata que, no início do século XX, na Alemanha, um professor de uma escola primária realizava, diariamente, exercícios nus ao ar livre com intuito de promover a saúde aos alunos. Aos poucos, segundo o referido autor, as crianças demonstraram um estado mais benéfico e saudável. Assim, os pais ficaram entusiasmados e começaram também, nas horas vagas, a praticar exercícios totalmente nus. Essa prática teria crescido e fundado o movimento "Culto do Corpo Livre ${ }^{6}$ ", sendo considerado a origem do naturismo na Europa.

O Naturismo, segundo Deschênes (2016) em seu artigo How the International Naturist Federation (INF) Defines Naturism publicado no website Young Naturists Ameri$c a$, naturismo é definido pela Federação Internacional de Naturismo em 1974, como: um modo de vida em harmonia com a natureza, caracterizado pela prática da nudez social, que tem por intenção encorajar o auto respeito, o respeito pelo próximo e o cuidado com o meio ambiente ${ }^{7}$.

Em toda esta definição, o que se torna figura nas sociedades urbanas é o termo "nudez social", porque o conceito guarda, em si, uma espécie de filosofia de vida, de uma postura provocativa para mudança do mundo, para construção de uma sociedade mais harmonizada na sua relação eu-mundo, em contraposição às sociedades urbanas, tecnológicas, consumistas, "antipessoais" (Perls, Hefferline \& Goodman, 1997, p. 141), baseada numa noção de corpo, simplesmente revestido a qualquer custo.

Essas sociedades vêm se caracterizando, cada vez mais, em "antipessoais" com seu rigor inalcançável e exigente de padrões corporais estéticos que têm provocado um verdadeiro massacre nas pessoas. Difícil sair deste personagem construído para movimentar bilhões de dólares das indústrias da moda, das chamadas "roupas de marca" e da beleza comprada. Não é de admirar que o consumismo se tornou uma das causas mais importantes na geração desta neurose de angústia baseada numa visão de corpo, ungido por alto investimento financeiro.

Tomada por estas inquietações, como não fazer referência a Dora Vivácqua, mais conhecida como Luz Del Fuego que foi uma das responsáveis pelo Movimento Naturalista Brasileiro. Segundo Pereira (2006, p. 121):

Em 20 de novembro de 1954, um ano após a fundação da I.N.F. ${ }^{8}$, em Montalivet, surge o marco definitivo do Movimento Naturista Brasileiro: Luz del Fuego cria,

\footnotetext{
${ }^{6}$ Frei Körper Kultur (FKK). Pouco depois o Nazismo teria proibido esse movimento por questões tanto mais políticas do que morais.

7 Naturism is a way of life in harmony with nature characterised by the practice of communal nudity with the intention of encouraging self-respect, respect for others and for the environment (Texto Original).

8 I.N.F. - Federação Internacional de Naturismo.
} 
no Rio de Janeiro, o Clube Naturalista Brasileiro. Os assentamentos do Partido e do Clube estão, conforme a Lei, no Registro Civil de Pessoas Jurídicas, nos livros A-3 e A-1. São fatos estabelecidos, inteiros e de fé incontestável.

Luz Del Fuego publicou dois diários, Trágico Black-out e $A$ Verdade $\mathrm{Nu}^{9}$ e a Revista Naturalismo. Nesta última afirmou:

A natureza nos exemplifica a vida... A hipocrisia e o preconceito, por conveniências e interesses, adoecem o corpo e a alma da humanidade.... Nascemos nus e nus vivem os índios no mais afervorado respeito a seus preceitos de moral. O naturismo exprime o caráter de tudo o que é real, do que é natural (Pereira, 2006, p. 125)

Pela coragem e novidade de suas ideias, ela foi reclusa em hospitais psiquiátricos por força da determinação dos irmãos que a julgavam insana. Havia uma transgressão impensável naquela acepção de moralidade e sabemos que toda transgressão se esvai, uma vez que haja sua legitimação. Para a sociedade de então, um corpo exposto era algo absurdamente impensável. Interessante lembrar o romance A Pata da Gazela de José de Alencar, em que faz referência ao jovem Leopoldo que se apaixona pelo tornozelo de uma moça. Partes do corpo não vistas, não expostas, sejam elas quais forem, se revestem de uma espécie de um proibido desejo, desperto por uma parte do todo que se torna uma figura proibida. Um desejo regido pela sedução do véu, do tecido que cobre e esconde e que se transforma na cena da sedução e da fantasia, que provoca sensações ligadas ao erotismo.

Estas reflexões nos permitem afirmar que o corpo nu não é, per se, indecente ou erótico. Em um espaço naturista, o estar nu parece, naturalmente, mais confortável do que em campos de nudismo facultativo. A sensação de uma unidade, de uma interconexão de todas as pessoas que ali estão é facilitada pelo corpo único que se forma, estando todos nus.

Tramita, atualmente, na Câmara dos Deputados, o Projeto de lei $\mathrm{n}^{0}$ 1.411, de 1996 de autoria do deputado Gabeira que fixa normas gerais para a prática do naturalismo e dá outras providências.

Art. $2^{\circ}$. Denomina-se naturismo o conjunto de práticas de vida ao ar livre em que é utilizado o nudismo como forma de desenvolvimento da saúde física e mental das pessoas de qualquer idade, através de sua plena integração com a natureza.

Parágrafo único: A atividade definida no caput deste artigo, em áreas autorizadas, não constitui ilícito penal.

\footnotetext{
9 O livro: A Verdade Nu está com suas edições esgotadas no Brasil, sendo vendido em poucas Casas de Sebo a um valor em torno de $\mathrm{R} \$$ 500,00 .
}

\section{(...)}

Art. $3^{\circ}$ Denominam-se espaços naturistas as áreas destinadas à prática do naturismo nas praias, campos, sítios, fazendas, áreas de campismo, clubes, espaços para esportes aquáticos, unidades hoteleiras e similares em que seja autorizada a prática do naturismo, em âmbito federal, estadual ou municipal.

O referido PL retira da categoria de "ilícito penal” áreas que sejam concedidas pelo estado para a prática de naturismo. Trata-se de um modo de regular o "como" e o "onde" ser-nú e o modo e o espaço do corpo despido. Inevitáveis leis regulatórias, que embora na contra-mão do "bom selvagem”, nos conduzem à prescrição regulatória necessária à própria segurança dos participantes do naturismo.

\section{Considerações finais: trilhas abertas entre linhas e letras nuas.}

Caro leitor, aqui me despeço tecendo algumas considerações finais a respeito dessa nossa caminhada. Não foi minha intenção seduzi-lo ou mantê-lo cúmplice desse modo de sentir, pensar, agir e expressar minhas inquietações, nem tampouco pretendi conduzi-lo à evidência alguma sobre a nudez social. Confesso, todavia, meu profundo respeito por nosso encontro nessas trilhas de linhas e letras à procura de sentidos que se travestem na nudez social.

Se Merleau-Ponty me faz compreender que a percepção é pré-conceitual, que nosso corpo tem a dimensão de nossa percepção, que o mundo estético se forma com a experiência e com a atividade do corpo próprio e, ainda, que este se constitui na convergência da percepção do mundo, como me parece ingênua a denegação da nudez social. O corpo-nu, em meio a outros em igual condição, talvez seja uma oferta única e generosa da natureza em busca de conter o potencial grau de destruição do humano em sua relação com o mundo.

No naturismo, muitos buscam por uma relação harmônica de simplicidade, de beleza, de equilíbrio e de paz. É uma forma de contato com o mundo, onde não basta a mim me ver como tal, eu preciso me doar e ser vista entre os meus iguais. Trata-se de uma troca e esta troca cria um campo experimental, experiencial, existencial e, às vezes até, transcendental, i.é, um campo de força que emerge da relação das pessoas com a natureza em estado de homeostase, onde a realidade relacional é produzida por variáveis psicológicas ligadas ao sentimento de conexão com a paz, a tranquilidade e a alegria de simplesmente existir. É esta a realidade fenomênica do naturista.

Neste campo, me dou conta de mim mesma, sou capaz de resgatar minha experiência de me sentir a mim mesma por meio de um processo de centragem, alargo minhas fronteiras da percepção própria, percebo a mim mesma como instrumento de cura e mudança, enraízo a noção 
de mim mesma, amplio minha consciência do meu corpo próprio e me faço sujeito de minha própria consciência.

A passagem de Merleau-Ponty (1974, p. 168), quando discorre sobre "a percepção e o diálogo" na obra "A Prosa do Mundo", é magnífica e assim se expressa:

O olhar que eu lançava pelo mundo, como o cego tateia os objetos com seu bastão, alguém os pegou pela outra ponta e os retorna contra mim para, por sua vez, tocar-me também. Não me contento mais em sentir, sinto que me sentem, e me sentem enquanto estou sentindo. (... como posso ver uma coisa que se põe a ver?

Foi unindo pensamento e sensibilidade como um caminho para a compreensão do ser-naturista que, para aquém da nudez cotidiana, em espaço reservado do mundo privado, necessito a nudez social, porque, talvez, não mais me baste sentir, preciso sentir que os outros me sentem.

Assim, imagino, aos moldes de Husserl, que cada momento do tempo possui uma fecundidade absoluta, sobretudo a arte das qualidades de ser único e de jamais deixar de ser sem ter sido. De igual modo, sei que o naturismo tem a petulância do tempo, jamais deixará de ser sem ter sido, pois que assim seja.

Retomando meu objetivo delineado para este estudo, qual seja de aproximar-me da essência do corpo-presença em Merleau-Ponty e, a partir daí, inferir algumas assertivas acerca da dimensão humana nesse tempo-espaço tortuoso no qual está contido o "tornar-se humano", na contemporaneidade, considerando o corpo-nú e o corpo-[re]vestido, me é possível afirmar que a prática do naturismo tem, para mim, a potência vital de me tornar mais humana, mais saudável em minha relação eu-mundo, mais livre para ser quem quero ser, mais respeitosa com outro e, sobretudo, mais feliz comigo mesma, porque, no naturismo, encontramos um viés para reconciliação entre nossas partes apartadas pelas sociedades antipessoais. No naturismo, sou uma totalidade existencial, de sentido, e a totalidade sou eu.

Assim sendo, tenho a honra de convidar Ribeiro, ou por outra, Jorge Ponciano, para proferir as palavras finais deste estudo e Chang-Tzu para, por meio da poesia, nos enlevar e nos conectar com as vozes dos ventos, das montanhas e das águas:

Tentar resgatar o ser humano, sem levar em conta que ele é, essencialmente, corpo- mente-meio ambiente, é desconhecer a verdadeira essência da pessoa e torná-la inatingível [...]. (Ribeiro (2006, p. 21)

Sopro da natureza

Quando a Natureza magnânima suspira

Que, silenciosos,

Despertam as vozes dos outros seres,
Soprando neles.

De toda fresta

Soam altas vozes. Já não ouvistes

O marulhar dos tons?

Lá está a floresta pendente

Na íngreme montanha:

Velhas árvores com buracos e rachaduras,

Como focinhos, goelas e orelhas,

Como orifícios, cálices,

Sulcos na madeira, buracos cheios d'água:

Ouve-se o mugir e o estrondo, assobios,

Gritos de comando, lamentações, zumbidos

Profundos, flautas plangentes.

Um chamado desperta o outro no diálogo.

Ventos suaves cantam timidamente,

E os fortes estrondam sem obstáculos.

E então o vento abranda. As aberturas

Deixam sair o último som.

Yu respondeu: Compreendo:

A música terrestre canta por mil frestas.

A música humana é feita de flautas e de instrumentos.

Que proporciona a música celeste?

Mestre Ki respondeu:

Algo está soprando por mil frestas diferentes.

Alguma força está por trás de tudo isso e faz

Com que os sons esmoreçam.

Que força é esta

Chuang-Tzu, citado por Merton (1969 p. 28)

\section{Referências bibliográficas}

Alencar, J. (1998). A pata da gazela. São Paulo: Ática, 15. ed.

Bello, A. A. (2000). Fenomenologia do ser humano: traços de uma filosofia no feminino. São Paulo: EDUSC.

Carvalho, M. A. B. (2013). Ecopsicologia e sustentabilidade: de frente para o espelho. Tese de Doutorado. Centro de Desenvolvimento Sustentável. Universidade de Brasília, Brasília.

Gênesis. In: A BÍBLIA: tradução ecumênica. São Paulo: Paulinas, 2002.

Ghiraldelli Jr, P. Intencionalidade Corporal? Texto para o PEPAS Retirado de: <http:/ghiraldelli.files.wordpress.com/ 2007/11/paulo_verss_jurandir.pdf $>$. Acessado em: 30 de março de 2014.

Leopoldi, J. S. (2002). Rousseau: estado de natureza, o "bom selvagem”e as sociedades indígenas. ALCEU, 2(4), p. 158-172.

Lyotard, J-F. (1979/2015). A condição pós-moderna. RJ: José Olímpio Ed.

Merleau-Ponty, M. (1974). O homem e a comunicação: a prosa do mundo. Rio de Janeiro: Bloch Editores.

Merleau-Ponty (1975). O Filósofo e sua Sombra. In: Textos EscoIhidos (Coleção Os Pensadores). São Paulo: Abril Cultural. 
Merleau-Ponty, M. (1999). Fenomenologia da percepção. São Paulo: Martins Fontes (Original publicado em 1945).

Merton, T (1969). Via de Chuang Tzu. Rio de Janeiro: Vozes.

Ministério da Cultura. Biblioteca Nacional. Departamento Nacional do Livro. Recuperado em: 24 de abril de 2015, <http://objdigital.bn.br/Acervo_Digital/livros_eletronicos/carta.pdf > .

Pereira, P. (2000). Corpos nus: o testemunho naturista. 2. ed. Rio de Janeiro: Leymarie.

Perls, F; Hefferline, R. \& Goodman, P. (1951/1997). Gestalt-terapia. São Paulo: Summus (Original publicado em 1951).

Ribeiro, J. P. (1997). O ciclo do contato. São Paulo: Ed.Summus.

Ribeiro, J. P. (2006). Vade-mécum de Gestalt-terapia: conceitos básicos. São Paulo: Summus.

Robine, J-M. (2006) O self desdobrado. Perspectiva de campo em Gestalt-terapia. São Paulo. Ed. Summus.

Rousseau, Jean-Jacques (1978). Do contrato social [1762]; Ensaio sobre a origem das línguas. 2. ed. São Paulo: Abril Cultural (Col. Os Pensadores), 1978. ed. São Paulo: Abril Cultural (Col. Os Pensadores).

Villamarín, A. J. G. (2003). Sucesso, paz interior e felicidade. Porto Alegre, AGE.

Zilles, U. (2002). Introdução de "A crise da humanidade européia e a filosofia”. Porto Alegre: EDIPUCRS.

Jorge Ponciano Ribeiro - Possui graduação em Filosofia Pura - Seminário Provincial de Diamantina (1955), graduação em Teologia - Seminário Provincial de Diamantina (1959), Mestrado em Psicologia - Ponteficia Università Salesiana (1972) e Doutorado em Psicologia Clínica - Ponteficia Università Salesiana (1975). Atualmente é professor titular aposentado da Universidade de Brasília. Tem experiência na área de Psicologia, com ênfase em Psicologia Clínica, atuando principalmente nos seguintes temas: psicopatologia, religiosidade, psicoterapia, ciclo do contato e Gestalt-terapia.

Marta Azevedo Klumb Oliveira - Possui graduação em Psicologia pelo Centro Universitário de Brasília (1990) e mestrado em Psicologia pela Universidade Católica de Brasília (2005). Especialista em Gestalt-Terapia (IGTB/DF); Especialista em Processos sócio-educativos com crianças e adolescentes (UFES/ES); Especialista em Educação de jovens e adultos - EJA (UnB) e; Especialista em Educação a Distancia (UFRJ). E-mail: martaklumb@gmail.com

Recebido em 04.08.16

Primeira Decisão Editorial em 30.09.16

Aceito em 26.02.17 